\title{
Student Socialization in the Age of Facebook
}

\author{
Louise Barkhuus \\ University of California, San Diego \\ 9500 Gilman Drive, La Jolla, CA 92093, USA \\ barkhuus@cs.ucsd.edu
}

\begin{abstract}
Most research regarding online social networks such as Facebook, MySpace, Linked-In and Friendster has looked at these networks in terms of activity within the online network, such as profile management and friending behavior. In this paper we are instead focusing on offline socializing structures around an online social network (exemplified by Facebook) and how this can facilitate inperson social life for students. Because students lead nomadic lives, they find Facebook a particularly useful tool for initiating and managing social gatherings, and as they adopt mobile technologies that can access online social networks, their ad-hoc social life is further enabled. We conclude that online social networks are a powerful tool for encouraging peripheral friendships, important in particular to students. We emphasize that the use of online social networks must be viewed from a perspective of use that involves both mobile and stationary platforms and that it is important to relate online and offline social practices.
\end{abstract}

\section{Author Keywords}

Social Networking, mobile applications, Facebook, Ubiquitous Computing.

\section{ACM Classification Keywords}

H.4.1: Information Systems Applications: groupware.

\section{INTRODUCTION}

Online social networks, particularly ones based on offline contacts, have recently received tremendous attention, both in the media and in research. Services such as Facebook, LinkedIn and MySpace have spread rapidly, motivating researchers to explore these in terms of different issues. Where some have looked at self-presentation [14, 16], others have looked at 'friending' and 'grouping' behavior within these networks [29, 32]. So far, the predominant focus has been on online activity, with a few exceptions, such as the exploration of online and offline integration in special interest network [37] and motivations for using online social networks in a work setting [15]. In this paper

Permission to make digital or hard copies of all or part of this work for personal or classroom use is granted without fee provided that copies are not made or distributed for profit or commercial advantage and that copies bear this notice and the full citation on the first page. To copy otherwise, or republish, to post on servers or to redistribute to lists, requires prior specific permission and/or a fee.

CHI 2010, April 10-15, 2010, Atlanta, Georgia, USA.

Copyright 2010 ACM 978-1-60558-929-9/10/04 ...\$10.00.

\author{
Juliana Tashiro \\ University of California, San Diego \\ 9500 Gilman Drive, La Jolla, CA 92093, USA \\ jtashiro@ucsd.edu
}

we focus exclusively on online social networks' use for offline face-to-face contacts. As a widespread social online network, Facebook is interesting to study because of its demonstrated strength of combining offline community with online community [25, 30]; its heavy use makes it relevant for research into structures and social practices. Today about $89 \%$ of US college students are members; the majority of students are active users of Facebook [18] and use it to maintain and build offline relationships $[25,30]$.

As a diverse user group, students possess a broad set of features that make them relevant for studying use of online social networks. They are unusually nomadic [3, 34]; they have classes and other academic activities at a variety of locations and at different times, often combined with working off-campus [34]. At the same time their social sphere is wide: they have multiple sets of friends and acquaintances, as well as school-related contacts (teachers, dorm managers etc.) with whom they have daily interactions [34]. They are therefore an interesting group of mobile workers to study in terms of how they integrate online social media into everyday life. In this paper we explore how university students integrate Facebook into their daily communication and social life.

In order to explore the offline behavior of students we build on earlier work exploring students' daily life and use of new technologies [3]. By studying students' use of Facebook as a communication tool, we aim to trace how students now incorporate Facebook into their array of everyday activities. We also draw on a recent ethnography of student life to illuminate the structures of mobile technology use among students [34]. We present a qualitative study of 18 college students, all users of Facebook. Through interviews and a 24-hour diary we gained insight into the mechanisms with which these college students access social networks as well as how this influences their social whereabouts and, in particular, how they organized their offline life around and through Facebook. Our results point to the obvious social benefits of online social networks, but more specifically to the frequent occurrence of serendipitous social meetings facilitated by Facebook. We describe in which ways students integrated (particularly mobile) use of Facebook into their lives and how Facebook was useful for maintenance of particular peripheral friendships. We talk about how the genre of online social networks lends itself well to casual socialization. Finally, we point out that it is important to 
view the use of online social networks together with other means of communication, as part of an offline life where face-to-face socialization occurs with the same people as communicated with through online social networks. Online social networks should also not be viewed in isolation from their diverse access technologies any longer; it is important to consider their use in relation to the many possible means of access.

\section{PREVIOUS RESEARCH}

Related research to our study ranges from studies about student life and students' use of technology to studies of use of online social networks.

\section{Student Life}

Traditional studies of student life tend to focus on academics [6] and student/faculty relationships [7]. Additionally, discussions and predictions regarding the effects of information technology on campus have mostly related to learning and academia [1]. One recent study that describes in depth the social structures of campus life from a student point of view is Rebekah Nathan's 'My Freshman Year' [34]. The ethnography was conducted by a professor who went 'undercover' as a freshman student at her own four-year university and experienced a full first year of university in 2002-2003. Because this ethnography was made before Facebook came about, Nathan used other technical means to communicate with her peers and classmates. One of her important findings is how students' lives are controlled to a high degree by scheduling. Nathan points out that not only do students often work on- or offcampus (half of her sample works part time up to 25 hours per week, corroborating national surveys), but they also take part in many extracurricular activities, such as professional clubs, athletics and special interest clubs (e.g. religious or volunteer activities). Their lives are therefore highly scheduled and they only have limited power, apart from initial scheduling of classes (each semester/quarter) to determine activities on an everyday basis.

A second finding, which few previous studies on student life have focused on, is that students also live very social lives. Although Nathan was surprised to discover how little students socialized with dorm-neighbors in the residence halls, they did socialize within other settings, such as special interest clubs, planned outings with previously known fellow students (such as high school friends), and ad-hoc socializing with new friends [34]. Combined with a very scheduled academic and work life, this meant that students' social lives were also fairly scheduled except for occasional serendipitous and ad-hoc meetings. Similar to other research findings, students had regular social gatherings (e.g. lunch, coffee between two classes) that leant on their class and work schedule.

Finally, students lead mobile lives, constantly moving from one place to another (classrooms to labs to work), making their lifestyle nomadic at best. In our previous work we found that it is particularly their lack of base that characterizes their behavior; where research addressing mobile work often assumes that mobile workers have a base, the experience of undergraduate students is radically different. [3].

\section{Students' Technology Use}

Even before online social networks were as widespread as they are today, students considered email beneficial for social relations in college life $[5,11,26]$. Other studies have showed that the Internet also helps students maintain close ties between family and friends, especially those too far away to visit in person on a regular basis, through, for example, instant messaging and chat programs [38, 20]. Baym et al., for example, looked at social uses of the Internet among US university students, however since the study predated Facebook they found no social interactions taking place through "newsgroups, MUDs, role playing games or any other Internet-enabled communication formats" [5]. Similarly, Quan-Haase studied Canadian student use of communication technologies, contrasting between local and far-away relations [38]; both studies found instant messaging a prominent environment for interacting. These two studies are particular snapshots of their time and location, both because they predate Facebook and because mobile phone providers' idiosyncrasies slowed down US adoption of mobile phone texting compared to Europe and Asia. Their conclusion that students prefer interactive, synchronous forms of online communication is thus hardly generalizable over time.

Students have often been early adopters of technologies, since they are young and in the process of becoming well educated and since many universities were pioneers in the use of computing, often opening up access to all students. As mobile phones became cheaper, they suited the nomadic structure of student life well and students adopted them rapidly. One study from 2006 showed that $97 \%$ of a US undergraduate student sample had mobile phones and used them widely to obtain social support; however, they were still more likely to seek face-to-face interaction with friends than using communication technology [20]. In terms of mobile technology use, it is noteworthy that despite the widespread use of students for studies of everyday use of technology (such as Dey and Guzman evaluation of presence displays [12] and Håkonson et al.'s evaluation of a mobile music sharing technology [24]; see also [4] for a discussion of overall use of students as test subjects), almost all the focus in such studies has been on academics. Studies have looked at in-class technologies [2, 39] and students use of electronic means for note-taking [40], but their integration of these technologies into their personal lives has yet to be addressed. An exception is Active Campus, a system that supports location-aware applications for students [22]; still, the main emphasis is on academic life (finding professors, finding classrooms). Finally, a few studies have looked at students' overall adoption of technology and found a high level of ownership of mobile 
devices and computing technology among both US students and Australian students $[10,27]$. We therefore aim to address this gap in the literature by exploring student life in a more holistic way.

\section{Online Social Networks}

Facebook was the first major online social network that was based on face-to-face relationships and collecting people who were part of an actual physical connection: the university [9]. Although social networks such as Orkut and Friendster existed before, these merely depended on general links between friends and were not concocted around a socio-geographic network. Even earlier, studies of social networks were often rooted in the notion of people's ability to communicate over long distances, connecting people with mutual interests regardless of physical location [42]. Initial academic descriptions of Internet communication focused on creating online communities, particularly understanding how strangers form personal relationships online [35] and defining the advantages of being able to collect and build friendships over distance through mutual interests [13, 42]. Before Facebook, social network sites tended to ignore location as a defining factor and focused on business connections (e.g., LinkedIn) or specific topics (e.g., support groups); exceptions were a few networks that specifically targeted local connecting (e.g., neighborhoods online [23]). Facebook was therefore not only a new type of online social network, it also targeted a group that had not been targeted as a coherent entity before: students at a particular university, without the oversight of university officials.

\section{Use of Facebook}

Ellison, Lampe and Steinfield have studied the use of Facebook amongst college students from several perspectives and it is here we find two exceptions to the paucity of studies of social life related to Facebook. In their 2007 study they find that social capital and social interaction was predicted by high self-esteem, satisfaction with university life and Facebook use; they suggest that Facebook may help individuals to maintain pre-existing close relationships [18], which our study explores in further depth. In their recent Interactions article, they discuss how online social networks can mobilize social action within special interest groups and grassroots political activities [19].

Most previous research, however, has focused on studying the characteristics of Facebook use not in isolation from social relations but in isolation from actual activities in users' lives. Facebook has been viewed as supporting online communication between real-life acquaintances and friends, but real-life communication that has been affected or negotiated by Facebook has been relatively ignored. Despite this lack, research has acknowledged that online social network activity is strongly connected with offline experiences [9, 37]. Furthermore, little, if any, research has so far addressed how Facebook is increasingly moving from the desktops into the palms of their users. Even Lampe, Ellison and Steinfield have yet to address the means with which the students in their studies are accessing Facebook. As we have noted, students have different lives from working adults; with socially complex nomadic lives and with the increase in smart phones, their use of social networking will likely be adjusted to mobile technologies. In our study we pay special attention to the different means students use to access Facebook.

\section{METHOD}

As our data we used interviews and short self-report diaries. We interviewed our participants for half an hour to an hour about their use of Facebook during a normal day, asking them to provide examples of how their social life was influenced by their use of Facebook. We also asked them to fill in a questionnaire about their use of Facebook over the last 24 hours, asking particularly about social meetings and social communication. Using elements of grounded theory [41], we analyzed the interviews in conjunction with the 24hour diaries by categorizing the different social events people described and comparing and contrasting their mobile access of Facebook. Our categorization was based on the data of this study but it was also held against data from our previous study where we had uncovered socialization amongst students [3]. The interviews and surveys were conducted between March and June 2009, all during term time to control for possible differences in behavior over final exams and holiday.

\section{Participants}

Participants were found through snowball sampling where one of the authors recruited students directly through classmates and via flyers on campus. We included 18 participants, 13 female and five male participants. All were students at our university, between 19 and 23 years old: one freshman, four sophomores, five juniors, seven seniors and one first year grad student. On average, the participants had been active users of Facebook for 2.9 years, mostly corresponding to their start at university. Being a public university, students were not necessarily affluent, but many still were able to acquire the latest technology in laptops and mobile phones. The criterion for taking part was being an active Facebook user. We looked for an equal number of users with Facebook available on their phone or not.

STUDENTS' MOBILITY AND ACCESS TO TECHNOLOGY 16 of our participants had a laptop, and while all 18 had a mobile phone, only eight had a mobile phone sufficiently advanced to access Web sites or applications from. Interestingly, the willingness to carry around a laptop on campus differed between participants, and hence affected their level of mobile access to Facebook. In accordance with our previous research [3] it was evident that students are nomadic and having a heavy laptop (subjectively judged by the individual) or lacking access to power during the day affected their inclination to bring it with them on their daily routine. Facebook was therefore semi-mobile for many 
students, with some students making intensive use of laptops during their daily activities around campus and between home and work. We therefore classified our participants individually as mobile (M), semi-mobile (SM) or non-mobile (NM) Facebook users. The mobile users were the eight participants who had mobile phones where they could access Facebook, all of whom used that method on a daily basis. The semi-mobile users were the five who tended to carry their laptop with them from place to place, using it in class, at coffee shops and in libraries for Facebook access (and other Web use) ${ }^{1}$. Finally, the last five participants were characterized as non-mobile, as they did not carry their laptop with them (if they had one) and primarily accessed Facebook from their home, work and occasionally from public PCs on campus, for example in the library.

\section{Mobile Phones}

Although it would seem as if financial constraints would affect student acquisition and use of mobile phones, it was surprisingly easy to find students with high-end phones with Internet browsers or third-party applications ${ }^{2}$. The most common was the iPhone (5), followed by the Blackberry (3). One participant, classified as semi-mobile, had an 'ancient' phone with Internet access, but reported accessing Facebook through it only on rare occasions. iPhone and Blackberry users all accessed Facebook via a downloaded application or, in one case, through the mobiletailored version of the Web site (m.Facebook.com). Our results are structured in relation to two main issues: Facebook as communication and Facebook's influence on social gathering.

\section{FACEBOOK AS COMMUNICATION}

\section{General use of Facebook}

Similar to students from other universities who reported Facebook to be part of their 'everyday activity' [31], most of our participants were heavy Facebook users. They estimated that they accessed Facebook between one and twenty times a day, on average 5.3 times a day for all participants. Differing across their access possibilities, the mobile users estimated that they accessed Facebook on average 6.9 separate occasions per day, the semi-mobile users 4.7 times and the non-mobile 2.6 times. These numbers should be viewed cautiously, since several of the users of desktops and laptops would $\log$ in at the start of a day and then keep a browser window open all day, looking for updates occasionally. This particularly happened on days when they were less mobile, such as on working days.

\footnotetext{
${ }^{1}$ Note that the university has an open campus-wide wireless network available to all students.

${ }^{2}$ It should be noted that virtually all data subscriptions in the US, where the study took place, are for unlimited Internet access at a fixed price, often around \$20 for data only.
}

However it is unsurprising that mobile users accessed it 'separately' more times per day than semi-mobile and stationary users, as they have Facebook in the palm of their hand throughout the day. Overall, mobile and semi-mobile users reported using Facebook more than non-mobile users.

Most of the participants reported using all the common features such as the Wall, messaging, status messaging and, in around half of the cases, also the built-in instant messaging. Two participants reported not updating their status more than a couple of times per week but the rest reported updating their status at least once per day.

\section{Communication Through Facebook}

Corresponding well to previous research we found our sample of students to have many social and academic activities [34]. These events, such as parties, coffee dates, professional club meetings etc. needed constant coordination. Students were also to a certain extent dependent on each other regarding schoolwork, such as obtaining notes and information when missing class. Communication (as with all other groups of people) was therefore essential and our participants used all available means, from email, course discussion forums and other Web services (e.g. wikis) to mobile phones, both voice and text. Participants had a tacit understanding of what means of communication was appropriate for what message, an aspect of communication media that media richness theory scholars have also pointed out [17]. These established practices showed themselves relevant to the participants' use of Facebook as well. Facebook was in many ways seen as 'just another means of communication'. Two of the participants used the analogy of texting (on a mobile phone) to describe Facebook's personal Wall function. One of them said: "I use [the Wall] to get a quick response or to tell my friend something like 'call me when you read this' [...] It's more like the type of things I might text to somebody" [M, female, grad student]. Previous research also points out the nature of text messaging being a communication means for 'lighter' relationships compared to voice calls [33]. Others had much lower expectations to how often their friends checked their 'Wall'; one participant explained that it was not optimal communication because it was not 'quick' enough, reasoning that people do not check their Facebook page all the time [SM, female, senior].

\section{Mobile Facebook}

Smart phones with usable Web browsing are relatively new, and although users have been able to access Web content via Web-enabled phones for almost a decade, Facebook became more readily available with its platform-specific applications for the iPhone and Blackberries. However, none of our eight mobile participants had owned a Webenabled phone prior to their current phone, except for the aforementioned participant with an 'ancient' Web-enabled phone. This corresponds well to a survey from 2005 where only $1.3 \%$ of students owned smart phones [10]). Instead, all were fairly new to mobile access of Facebook: one 
participant reported having had access to Facebook on her mobile device for more than a year and three between six months and a year ago. Four had only had the mobile access method available for about a month, corresponding to their acquisition of iPhones or Blackberries. These new users reflected on their habits and reported that they accessed Facebook much more now than before acquiring the mobile device. One participant said she used Facebook more since she got her Blackberry, but she also described that she used it differently: "I use mostly just the Wall... changing my status and looking at new photo uploads when I am on my Blackberry [...] Maybe 'cause when I am using my [Blackberry] I don't have as much time so I'm just kind of browsing or responding to a friend really quick" $[\mathrm{M}$, female, senior]. She also observed that her friends had changed habits as they had acquired mobile devices and were now faster in answering or responding to content on their Facebook pages.

With the Facebook application available for the iPhone and Blackberries it was very easy for participants to check updates and most of the mobile participants expressed that they would often just click on the application "to see if anything interesting had happened." On their laptop, on the other hand, they would spend longer, browsing pictures and taking quizzes, but would only do this once or twice a day.

Both mobile and semi-mobile users expressed great satisfaction in being able to access Facebook while out during the day. They reported accessing Facebook with whatever means was available. One participant said: "I'd wake up... since I'd be in bed and not want to get out I might access Facebook on my Blackberry... you know cause it's there next to my bed... and then later in the day after getting ready for school I would access it on my laptop like in class, or in between. Sometimes while walking to class I will access Facebook on my Blackberry. After class I usually go to work, so I'll access it there" [M, female, senior]. Considering under what circumstances participants used the mobile device over a laptop or desktop, another explained: "I just use whichever one is more convenient. Sometimes I'll use my iPhone if my laptop isn't near, but if I have to send out a message or upload pictures I have to use my laptop" [M, female, junior].

The mobile technologies available to the students such as laptops and mobile phones were well integrated into each student's lifestyle. And in contrast to our earlier studies, where students reported laptops being too heavy [3], the last few years have seen lighter laptops, including the small 'netbooks', making it possible for more students to carry these with ease. We found mobile and semi-mobile users use Facebook in shorter 'bursts' than when dependent on a desktop, remaining constantly 'in touch' with a large set of friends and acquaintances. Facebook was very integrated into students' communication patterns; they used it for maintaining their social life, scheduling meetings in professional clubs or volunteer work or arranging studyrelated meetings or class-related information exchange.
They were very loyal to Facebook; under probing, they all insisted that it was necessary in order to keep in touch with all their friend and acquaintances. One participant said: "It helps me keep in touch with my friends, and if I didn't have [Facebook], honestly I would feel out of the loop."

\section{SOCIAL GATHERING AND FACEBOOK}

From our data, as well as that of previous studies [3, 34], we identified four different types of social gatherings or events that were useful for our further analysis of Facebook's facilitation in students' everyday life.

Scheduled social gathering: These gatherings included sorority meetings, volunteer events or other meet-ups that were partly social but often had a practical purpose too (e.g. planning other events). These were often recurring events. They were frequently planned through Facebooks 'event' function, where one participant would set up an event and invite relevant members.

Semi-scheduled social gathering: These types of gatherings included regular lunch dates or 'pick me up from class' socializing. Most often these were highly structured and regular; since students have the same classes for a semester/quarter and know each others' schedules, these were mostly facilitated simply by regular scheduling or by mobile phone, text messaging or voice.

Ad-hoc social gathering: This included spur of the moment meet-ups and short-time planned meet-ups. Students often bump into each other on campus or around housing, leading to ad-hoc socializing, but also short-term plans (such as planning to have lunch the next day) would fall under this category. Facebook status messages were found to facilitate these types of meetings in particular.

Special events: These events are bigger and rarer events often based on actual invitations. They were birthday parties, for example, or a barbecue that had been planned for a while. These events were often facilitated by Facebook's 'events,' but we also found them facilitated well by Facebook's status messages, as will be elaborated on further down.

\section{Facilitating Peripheral Friendship}

Facebook has been named as particularly valuable in supporting users' management of so-called 'weak ties,' [21] social connections that are peripheral (friends of friends, remote colleagues, past classmates) $[16,19]$. We found several examples of this type of 'functional maintenance' of relationships with peripheral people in the participants' lives. One participant, for example, found it particularly appropriate as a communication mechanism when she was involved in recruiting newcomers for her sorority. She explained that she normally would not think of telephoning many of the people on her Facebook friend list, but felt fine about communicating with them through Facebook: “...we arrange outings together on Facebook, 'cause like you know, we all just meet each other and personally I guess I 
would feel weird calling them up. [...] It helps me to [...] forge better bonds with people I just met... or barely see..." [M, female, senior]. Another participant used her peripheral Facebook friends when she needed notes for a class she had missed: "There was a girl that I knew in the class I needed notes for a lecture that I didn't go... so I searched for her [on Facebook] and I sent her a message like 'hey I need the notes for class' and like yeah... [I use Facebook messages] usually when I just need like notes" [SM, female, senior].

In our study we found that social gatherings were arranged through a mixture of the communication means available; Facebook was yet another way of arranging get-togethers. Participants used the event functions, and were keen on inviting friends more or less formally through Facebook's other mechanisms (such as groups and Wall postings) as well. Facebook particularly functioned as a 'buffer' for arranging ad-hoc social meetings with people the students were not that close to. One participant said for example: "[T]here are some friends that I would message on Facebook to hang out, but would never call to ask them. [...] Like, we aren't super close so, like I might be like, "hey do you want to chill later this week" and then if they say yes then we might plan something. I just wouldn't feel comfortable calling them" [NM, male, senior]. For another participant, Facebook worked as a tool for communication with people he did not necessarily want close relationships with: "even if I don't know the person that well, so I don't have their number, I might comment them something [on their wall]" [M, female, graduate student].

Facebook's 'event tool' enables members to invite a selected set of Facebook friends and to specify the time and date in order for invitees to receive reminders. Interestingly, the event tool was mainly used when participants were planning and attending larger events such as birthday parties (special events) or, for example, structured sorority events (scheduled social gathering). However, the majority of social gathering that occurred was, as other descriptions of student life suggest, ad-hoc gathering or semi-scheduled social gatherings.

So far our data support previous studies in regards to how Facebook is used to support offline ties and connections. In addition, we found that Facebook can be used to leverage other means of communication when lightweight interaction is preferred. Similarly to the way in which text messages were often used in cases where phone calls would not necessarily have been placed before ('grooming') [33], communication through Facebook is often characterized by being 'extra' communication. This does not mean that the communication is insignificant; in fact, as Nathan also describes, peripheral friends are very important to students' university experience [34]. Before discussing social gatherings in more detail, we will discuss the possible side effect of the personalized, often location-defining status message.

\section{Status Messages and Uninvited Meetings}

Although the status message in Facebook is free text, it is common for online social network users to describe their present activity, often implying location [36] ('working out at the gym', 'studying at the library' etc). Research also reports that users occasionally, by accident, give out too much information and experience unwanted approaches [ibid]. Rather than focusing on unwanted approaches, we asked our participants if they ever interpreted a locationdefining status as an invitation, and if they had ever used a local friends' status message to 'stop by' a place they reported being at. Interestingly, three participants reported this as being "a bit creepy." One participant said that "it would be awkward to just show up" [NM, male, senior] and another participant responded that "it seems too stalker-like to just appear at the place where someone is because they put their status there" [SM, female, sophomore]. So although participants reported often stating directly or indirectly their location in their status, we found evidence of strong unwritten rules in terms of uninvited social gatherings. Instead, they would use the status message as a catalyst for further communication by, for example, sending a text message responding to the status, eventually leading to an ad-hoc social gathering.

\section{Facilitating Social Gathering Through Status Messages}

We found that one of the non-mobile, two of the semimobile and three of the mobile participants had used Facebook to facilitate meeting up with people during the last 24 hours before their interview. The interviews also uncovered older incidents of such connections, and all in all ten of the 18 participants could recall specific incidents of using Facebook status messages to facilitate a face-to-face social gathering. While all of these were initiated by somebody's status message, they were also all facilitated by other communication means such as text messages and phone calls. All in all we had 15 specific examples of this type of meet-up. We can separate the incidents of coordinating behavior into three categories: 'spur of the moment meeting,' 'meeting reminders' and 'social assistance.'

\section{Spur of the Moment Meetings}

As described above, the status messages provided valuable social information for participants particularly for ad-hoc social gathering. Sometimes they were direct invitations resulting in spur of the moment meetings: "The other day my friend put a post 'Wanna go out for taco Tuesday? Call me!' so I called my friend and we went that night together (laughing) I guess that sounds weird like inviting myself (laughing)" [M, female, senior]. Instead of directly asking specific individuals, this participant's friend relied on her local social network to respond. So although the participant felt as she was inviting herself, her friend had already provided an open invitation, making it easier for her to respond. Other status messages resulting in real-life encounters were less direct in their invitation. One participant's friend simply stated 'hungry,' causing the 
participant to reply with a text message. Subsequently they met up an hour later. Similarly, a participant reported seeing a friend's status: "My friend and I were both studying for midterms a few weeks ago, and then she put in her status 'need caffeine', so I replied and said that we should go get Starbucks. So we went" [SM, female, sophomore]. Our favorite example was a participant who was selling chocolates for charity. She entered in her statusmessage from her iPhone that she was in the library on a particular floor selling chocolates and encouraged people to stop by. She reported that four people had stopped by to buy chocolate during the hour and a half she had been there.

Notably, the majority of these 'spur of the moment meetings' were facilitated by mobile use of Facebook, and this connection was not found among non-mobile users. One non-mobile user reported that he sometimes sent friends messages on Facebook to see if they wanted 'to do something,' but that this would be for planning future events, not something that same day [NM, male, senior].

\section{Meeting Reminders}

Status messages also facilitated meetings by reminding participants about previously arranged events such as parties or meetings (special events). These were not necessarily 'events' on Facebook, but status messages helped friends remember social gatherings. One participant explained: "One of my frat brothers had put in his status that he was at a barbeque at the beach [...] If I did [sic] not see my friend's status I would have completely forgot about his barbeque" [NM, male, freshman]. Another participant explained that she was promoting a club, and on nights where the club had events, she made sure to mention this in her status. In return, many of her Facebook friends would contact her and ask to be put on the guest list.

\section{Social assistance}

We also found examples of Facebook content prompting social activities by people who claimed they would not have attended otherwise, mostly special events. One participant explained that she was hesitant to go to a party. But when she saw a close friend's status indicating she was going, the participant called her up so they could go together. She said she would feel awkward going and not knowing anyone [M, female junior]. Another participant put it in more general terms: "If my friend put that she's going to an event that I wanted to check out as well $[\ldots]$ like the seminars or like lectures [...] sometimes I want to check them out ... but I hate going to those kind of things by myself" [NM, female, junior]. The casualness with which students can decide on social activities based on their friends' indications made Facebook a useful facilitator for shy and less extroverted students. This relates well to the findings of Ellison et al. that emphasize how self-esteem was facilitated by Facebook interactivity [18].

Table 1 shows an overview of the different types of coordinating behavior that Facebook was found to facilitate.
Note that we did not find any specific examples of facilitation of scheduled social gathering although it is apparent that Facebook could easily support this.

\begin{tabular}{|l|l|l|}
\hline & $\begin{array}{l}\text { Examples found } \\
\text { in study }\end{array}$ & $\begin{array}{l}\text { Likely to be supported } \\
\text { but no examples found }\end{array}$ \\
\hline $\begin{array}{l}\text { Spur of the } \\
\text { moment } \\
\text { meetings }\end{array}$ & $\begin{array}{l}\text { Social ad-hoc } \\
\text { gathering }\end{array}$ & Scheduled social \\
\hline $\begin{array}{l}\text { Meeting } \\
\text { reminders }\end{array}$ & Special events \\
\hline $\begin{array}{l}\text { Social } \\
\text { assistance }\end{array}$ & Special events & \\
\hline
\end{tabular}

Table 1: The support Facebook provided in relation to the different types of social gathering

\section{DISCUSSION}

For most of our participants, Facebook was well integrated into their usual communication infrastructures including mobile phone, email and IM. It has become embedded into the setting, and to many students almost 'invisible' participants sometimes struggled to specify exactly how they communicated in particular situations. Yet it facilitated numerous instances and types of social activities, particularly ad-hoc social gatherings and special events. In our discussion we want to highlight three issues that are important when considering Facebook as a social facilitation tool. First, we point out that to students 'friends' does not denote a fixed set of people but instead has a fluid definition. Next we highlight the importance of peripheral social relationships. Finally, we discuss why Facebook is so well tailored for use by students to organize their lives.

\section{Student's Notion of Friendships}

University students are at a stage in life where their social life is pivotal to their quality of life. It is also a time where friendships are made, maintained, broken and perhaps revived. Interestingly, from our data it was evident that "friendship" was an oversimplified label for a more complex and diverse set of relationships. Students used Facebook to not only plan socialization with friends but also to overcome their shyness over contacting peripheral friends directly. As Nathan also describes, students often have a set of five or six close friends, but these friends also had similar sets of close friends that did not necessarily overlap, making friends of friends "acquaintances" or peripheral [34]. As boyd have pointed out previously in connection with other online social networks [8], friendship is a flexible notion; peripheral friendships can grow into closer friendships and Facebook, in this sense, was a practical facilitator for precisely this process. Students were more likely to request casual socialization, or even broadcast 'invitations' to their entire network, through Facebook than by telephoning. It was also considered easier for someone to respond to such an informal invitation. Although Facebook does not distinguish between close and 
peripheral friends ${ }^{3}$, it facilitates well the building and management of all types of friends through the control that each user has over their communication through Facebook. The plausible deniability that automatically comes with an online social network (as with most asynchronous communication) made it ideal for many levels of friendship.

We also found that in particular mobile and semi-mobile access to Facebook facilitated ad-hoc social gathering owing to its constant availability in the nomadic students' lives. Students could keep up with opportunities as well as if they were in front of a computer all day (which some also were occasionally due to work). Facebook was in many ways used to 'do' friendship, maintain it and adjust it. This brings us onto the importance of students' light social relationships.

\section{The Importance of Peripheral Social Relationships}

Being young and in college is difficult; college students have to negotiate both strict time constraints and a multitude of social engagements. It is important to students to be popular, and complicated to know how to fit in. For this population Facebook functions as a buffer for much communication around social engagements. It is not just a practical means of communication; it also makes social gatherings undemanding, which is important in order to keep some relationships light. Where previously, college students might have had specific spots on campus where their 'crowd' would gather, it is now possible to casually keep up these light social relationships with a more fluid physical location (and students might still have places where they gather). In our study we found Facebook to be a great tool for shy students or students who just simply did not feel close enough to certain other people to telephone them. These light relationships are essential for student life in that they 'make' the community that Nathan describes as missing in the dorms. The community is not missing, as she first believed; it was to be found places other than physical areas. It was not the dormitory hallways that created community but instead students' peripheral acquaintances that made up one's community [34].

In order to understand student life it is therefore essential to understand students' social relations. By highlighting the importance of peripheral social relations we hope to have provided further insight into students' motivations for using Facebook and its integration into their everyday life. Finally we discuss why Facebook is so well integrated into student life.

\footnotetext{
${ }^{3}$ Facebook does in fact allow users to define group of friends and enable limits on specified friends' access to personal data. However, this functionality does not relate to actual communication through Facebook.
}

\section{Interweaving Facebook into Everyday Student Life}

Facebook is probably, even more than other communication means, the glue in many students' life. Where previous research has focused on Facebook as a tool for specific tasks such as 'keeping up with friends' or 'searching for new friends', we have attempted to provide a more holistic overview of how Facebook influences and facilitates reallife behavior. It was clear that students were able to weave Facebook into their nomadic life, particularly if they had mobile or semi-mobile access. In a sense Facebook had become an infrastructure for facilitating certain types of social gatherings. Still, since none of the socialization (specifically described as well as generally described by our participants) was facilitated solely via Facebook, it did not work as an independent communication infrastructure.

Facebook was integrated thoroughly into student life because of high technology adoption rate and of availability (of computers, network etc.), but more importantly it was integrated because (nomadic) student life lends itself to non-orderly social behavior. Students need reminders for events, incentives for social gatherings (e.g. a close friend is also going) and facilitators for ad-hoc meetings, particularly very sporadic ones. Despite being busy, they are also (and want to be) highly social, and Facebook helps them to achieve that.

Finally, location was key to Facebook's integration into students' life. Ad-hoc socialization is highly dependent on partners being located in the same area, which by nature many students are, at least during term time. Where previous online social networks attempted to collect members despite distance, Facebook collects people because of nearness and therefore results in members using it for real-life social gatherings. Location helps the incorporation of Facebook into student lives.

\section{CONCLUSION}

In this paper we set out to take a closer look at Facebook's integration into students' social practices, particularly in relation to different modes of access to Facebook. It is particularly meaningful for students to use Facebook on the go because of their already nomadic lifestyle. We found that they use the advantages that mobile or semi-mobile access provides, especially in relation to negotiating relationships: peripheral relationships, closer friendships, and school- or organization-related relationships (although it should be noted that we did not find any evidence of faculty/student communication through Facebook).

An interesting finding was that, amongst our participants, the Facebook users who were also using mobile or semimobile devices were indeed using Facebook more for arranging particularly ad-hoc social gatherings. This likely stems from the ready opportunities they have throughout the day to stay updated while out being mobile. The nonmobile users used Facebook for social facilitation for events that were less spur-of-the-moment and more planned, such as special events. This does not automatically imply that 
mobile access leads to a richer social life; students who use Facebook more for social life facilitation could also be more likely to acquire mobile or semi-mobile communication technology. Also it should be noted that given our small sample, it is not possible to observe statistically significant differences.

The finding that Facebook was used to facilitate ad-hoc social gathering shows how online social network interaction 'spill over' into real life, not as an exception, as described by Wellman [42], but as a normal continuation of communication through the online social network. It is an attribute of offline-based online networks that people communicate through multiple means and the online network then becomes yet another means.

The strength of Facebook, as demonstrated in our study, was that its genre lent itself well to casual interaction online, leading to casual interaction offline. The genre of Facebook is illustrated through for example its 'Wall' and the ability to 'poke' a friend, items that give users a sense of informality and lightness. Facebook practically supported communication between those who were not close, since it does not require the exchange of email addresses or phone numbers. Moreover, messages (as well as wall posts and pokes etc.) sent through Facebook can be ignored in a way that a phone call cannot. Facebook as a genre also (by its very nature) engages notions of friendship and conviviality, rather than, for example, the connections between work and email or the intimacy of a text message.

Finally, our findings point to the importance of considering platform and access mechanism when researching online social networks. Even the difference in level of access means that the experiences are quite distinct; the type of access transforms a longer-lasting, thorough experience, exploring pictures and other people's details, to a lightweight experience, a simple checking of status and personal messages. It is therefore essential to examine online social network use in relation to these new technologies and from a more holistic viewpoint.

\section{ACKNOWLEDGMENTS}

We thank the participants for their time.

\section{REFERENCES}

1. Agre, P. Infrastructure and Institutional Change in the Networked University. Information, Communication, and Society 3(4), 2000, 494-507.

2. Anderson, R. Anderson, R. Simon, B., Wolfman, S VanDeGrift, T. and Yasuhara, K. Experiences with a Tablet PC Based Lecture Presentation System in Computer Science Courses. In Proceedings of SIGCSE 2004.

3. Barkhuus, L. and Dourish. P. Everyday Encounters with Context-Aware Computing in a Campus Environment. In Proceedings of UbiComp 2004, pages 232-249. Springer.
4. Barkhuus, L. and Rode, J. From Mice to Men: - 24 years of Evaluation in CHI. alt.chi, 2007. Available at: http://www.itu.dk/people/barkhuus/barkhuus-altchi.pdf

5. Baym, N. K., Zhang, Y. B. and Lin, M. C. Social Interactions Across Media: Interpersonal Communication on the Internet, Telephone and Face-toFace. New Media Society, 6 (2004), 299 - 318.

6. Becker, H., Geer, B. and Hughes, E. Making the Grade: The Academic Side of College Life. Wiley, New York, US, 1968.

7. Bess, J.L. Integrating Faculty and Student Life Cycles. Review of Educational Research. 1973; 43: 377-403. Sage.

8. boyd, d.. 2006. "Friends, Friendsters, and MySpace Top 8: Writing Community Into Being on Social Network Sites." First Monday 11:12, December.

9. boyd, d and Ellison, N. Social Network Sites: Definition, History and Scholarhsip. Journal of Computer-Mediated Communication. 13 (1), pp. 210230. 2007, Wiley.

10. Caruso, J. B. \& Kvavik, R. (2005). ECAR study of students and information technology 2005: Convenience, connection, control, and learning. EDUCAUSE.

11. Cummings JN, Butler B, Kraut R. 2002. The quality of online social relationships. Communication of the ACM 45(July): 103-8.

12. Dey, A. K. and de Guzman, E. 2006. From awareness to connectedness: the design and deployment of presence displays. In Proceedings of $\mathrm{CHI}^{\prime}$ '06. ACM, New York, NY, 899-908.

13. DeYoung, B., Harris, P. and Larsen, L. Virtual Communities and University Outreach. Journal of Extension. 33 (1), February 1995, Available at: http:/www.joe.org/joe/1995february/a5.php

14. DiMicco, J.M. and Millen, D.R., Identity management: multiple presentations of self in Facebook. In Conference on Supporting Group Work, (Sanibel Island, FL, 2007), ACM Press, 383-386.

15.DiMicco, J., Millen, D. R., Geyer, W., Dugan, C., Brownholtz, B., and Muller, M. 2008. Motivations for social networking at work. In Proceedings of $C S C W$ '08. ACM, New York, NY, 711-720.

16. Donath, J. and boyd, d. Public Displays of Connection. BT Technology Journal, 22 (4), October, 2004, 71-82.

17.El-Shinnawy, M., Markus, M. L. The Poverty of Media Richness Theory: Explaining People's Choice of Electronic Mail vs. Voice Mail. International Journal of Human Computer Studies. 1997, 46 (4), 443-468.

18. Ellison, N. B., Steinfield, C., \& Lampe, C. (2007). The benefits of Facebook "friends:" Social capital and college students' use of online social network sites. 
Journal of Computer-Mediated Communication, 12(4), article 1 .

19.Ellison, N. B., Lampe, C., and Steinfield, C. 2009. Social network sites and society: current trends and future possibilities. Interactions 16, 1 (Jan. 2009), 6-9. ACM Press.

20. Gemmil, E. and Peterson, M. Technology use among College Students: Implications for Student Affairs Professional. In NASPA Journal, 2006, 43(2).

21. Granovetter, M. The Strength of Weak Ties. American Journal of Sociology. 78 (6), 1973, 1360-1380.

22. Griswold, W. G., Shanahan, P., Brown, S. W., Boyer, R., Ratto, M., Shapiro, R. B. and Truong, T. M. ActiveCampus: Experiments in Community-Oriented Ubiquitous Computing, Computer, 37(10), 73-81, Oct. 2004.

23. Hampton, K. N. and Wellman, B. (2002) The Not so Global Village of Netville. In Barry Wellman and Caroline Haythornthwaite (Eds.) The Internet and Everyday Life. Oxford, UK: Blackwell.

24.Håkansson, M., Rost, M. and Holmquist, L.E. Gifts from Friends and Strangers: A Study of Mobile Music Sharing. In Proceedings of ECSCW 2007, Springer, 311-330.

25. Joinson, A. N. 2008. Looking at, looking up or keeping up with people?: motives and use of Facebook. In Proceeding of CHI '08. ACM, New York, NY, 10271036.

26. Jones S. 2002. The Internet Goes to College. Washington, DC: Pew Internet/Am. Life Proj. http://www.pewInternet.org

27. Kennedy, G.E., Judd, T.S., Churchward, A., Gray, K. and Krause, K.L. First year students' experiences with technology: Are they really digital natives? Australasian Journal of Educational Technology, 2008, 24(1), 108122.

28. Kozma, R. B. Technology and Classroom Practices: An International Study. In Journal of Research on Technology in Education. Vol. 36, 2003.

29. Lampe, C., Ellison, N. and Steinfield, C., A Face(book) in the Crowd: Social Searching vs. Social Browsing. In Proceedings of CSCW 2006. ACM, New York, NY, 167-170.

30.Lampe, C. A., Ellison, N., and Steinfield, C. 2007. A familiar face(book): profile elements as signals in an online social network. In Proceedings of CHI '07. ACM, New York, NY, 435-444.
31.Lampe, C., Ellison, N. B., and Steinfield, C. 2008. Changes in use and perception of facebook. In Proceedings of $C S C W^{\prime} 08$. ACM, New York, NY, 721730.

32.Lampinen, A., Tamminen, S., and Oulasvirta, A. 2009. All My People Right Here, Right Now: management of group co-presence on a social networking site. In Proceedings of GROUP '09. ACM, New York, NY, 281-290.

33.Ling, R. The Mobile Connections. Morgan Kaufman, 2004.

34. Nathan, R. My Freshman Year. What a professor Learned by Becoming a Student. Penguin Books, 2005.

35.Parks, M. R. and Floyd, K. Making Friends in Cyberspace. In Journal of Computer-Mediated Communication. 1 (4), March 1996. International Communication Association.

36.Patterson, D. J., Baker, C., Ding, X., Kaufman, S. J., Liu, K., and Zaldivar, A. 2008. Online everywhere: evolving mobile instant messaging practices. In Proceedings of UbiComp '08, vol. 344. ACM, New York, NY, 64-73.

37.Ploderer, B., Howard, S., and Thomas, P. 2008. Being online, living offline: the influence of social ties over the appropriation of social network sites. In Proceedings of CSCW' 08 . ACM, New York, NY, 333-342.

38. Quan-Haase, A. University Students' Local and Distant Social Ties - Using and integrating modes of communication on campus. Information, Communication \& Society, 10 (5), 2007, 671-693.

39. Ratto, M., Shapiro, R.B., Truong, T.M. and Griswold, W.G. The activeclass project: Experiments in encouraging classroom participation. In Proceedings of CSCL 2003.

40. Simon, B., Davis, K., Griswold, W. G., Kelly, M., and Malani, R. 2008. Noteblogging: taking note taking public. In Proceedings of SIGCSE' '08. ACM, New York, NY, 417-421.

41. Strauss, A. and Corbin, J. Basics of Qualitative Research. Sage, 1998.

42. Wellman, B., Quan-Haase, A. Boase, J., Chen, W., Hampton K., de Diaz, I.I. and Miyata, K. The Social Affordances of the Internet for Networked Individualism. In Journal of Computer-Mediated Communication. 8 (3). April 2003. 